

\title{
INTRODUCTION TO LINGUISTICS
}

\author{
SILPIA RAHAYU
}

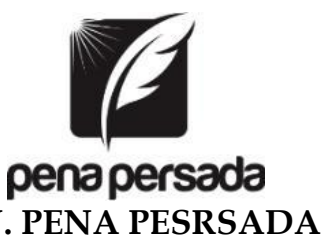




\section{INTRODUCTION TO LINGUISTICS}

\section{Penulis :}

Silpia Rahayu

ISBN : 978-623-6837-05-4

Design Cover :

Retnani Nur Briliant

Layout :

Hasnah Aulia

\section{Penerbit CV. Pena Persada \\ Redaksi :}

Jl. Gerilya No. 292 Purwokerto Selatan, Kab. Banyumas Jawa Tengah

Email : penerbit.penapersada@gmail.com

Website : penapersada.com

Phone : (0281) 7771388

Anggota IKAPI

All right reserved

Cetakan pertama : 2020

Hak cipta dilindungi oleh undang-undang.

Dilarang memperbanyak karya tulis ini dalam bentuk dan cara apapun tanpa ijin penerbit 


\section{PREFACE}

Language is all around us. Language allows us to share complicated thoughts, negotiate agreements, and make communal plans. Our learning, our courting, our fighting - all are mediated by language.

You can think of language as a technology - humans manipulate their bodies to produce sounds, gestures, and appearances that encode messages using a shared system.

How then does the technology of language work? Answering this question is surprisingly hard; our language skills are automatic and therefore hard to reflect upon. Nevertheless, throughout the centuries, scholars have devised ways to study human language, although there is still much more research to be done and many mysteries to explore. The field of scholarship that tries to answer the question "How does language work?" is called linguistics, and the scholars who study it are called linguist.

This book contains various aspects of Linguistics. Started from the understanding of Linguistics, until the kinds of Linguistics. Students are expected to be able to understand Linguistics after they read this book.

Cimahi, September 2020

Author 


\section{TABLE OF CONTENTS}

PREFACE .................................................................................. iii

TABLE OF CONTENT …................................................. iv

CHAPTER 1 DEFINITION AND BRIEF EXPLANATION ABOUT LINGUISTICS

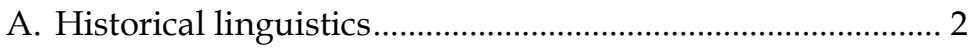
B. Studying linguistic structure.................................................. 5

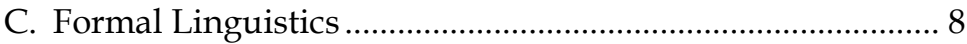
D. Formal linguistics includes five principal areas

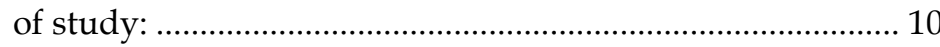

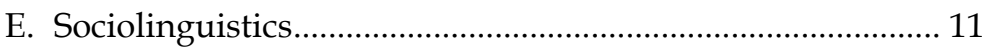

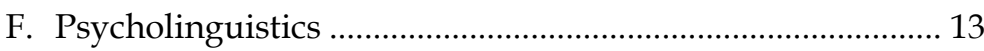
G. Applied Linguistics .................................................................. 14

CHAPTER 2 LINGUISTICS IN GENERAL

A. Syntax and morphology ..................................................... 15

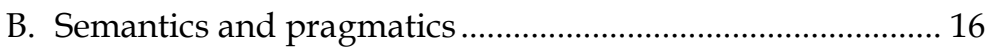

C. Phonetics and phonology ..................................................... 17

D. Language varieties............................................................... 17

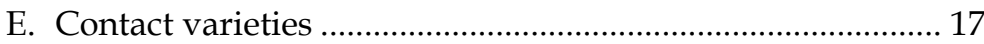

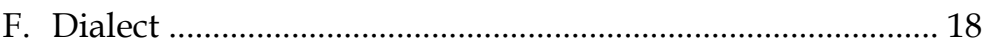

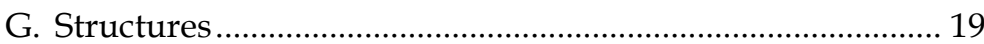

H. Hidden knowledge: how linguistic inquiry works .............. 19

I. Case study 1: English plurals ................................................. 20

J. The idea of deep structure and the general outline of

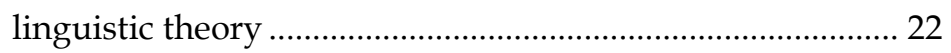

K. Case Study 2: The English auxiliary wanna.......................... 22

\section{CHAPTER 3 MICRO AND MACRO LINGUISTICS}
A. Macrolinguistics 26
B. Microlinguistics 26

\section{CHAPTER 4 PHONETICS PHONOLOGY}

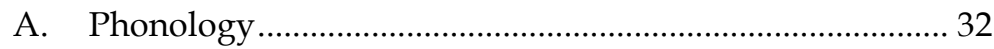

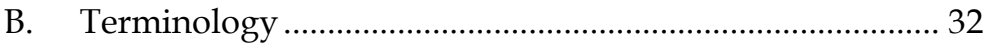

C. Derivation and definitions ................................................. 33

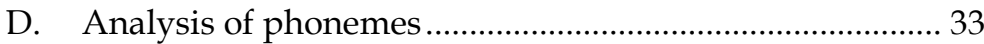

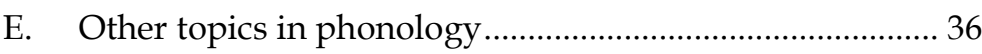

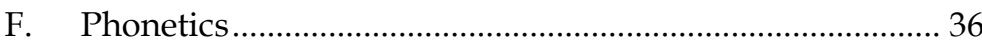




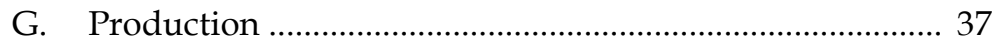

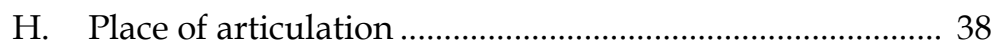

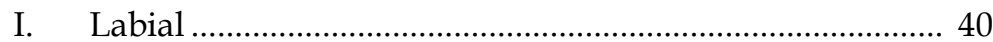

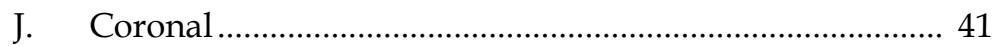

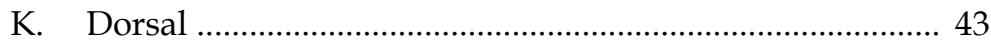

L. Pharyngeal and laryngeal ................................................... 44

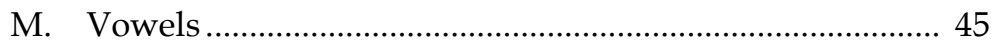

N. Manner of articulation........................................................ 46

\section{CHAPTER 5 MORPHOSYNTAX}

A. Fundamental concepts .......................................................... 50

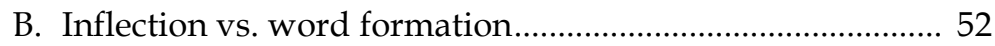

C. Types of word formation ..................................................... 53

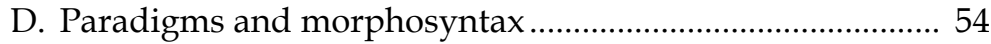

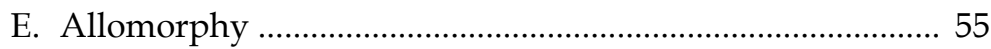

F. Lexical morphology ............................................................. 56

\section{CHAPTER 6 SEMANTICS}

A. Theories in linguistic semantics ........................................... 61

\section{CHAPTER 7 PRAGMATICS}

A. Maxims of Conversation ...................................................... 71

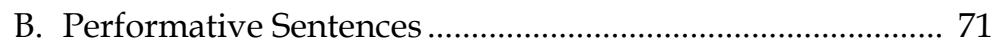

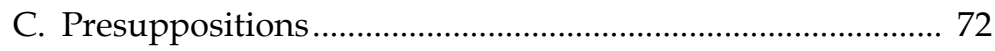

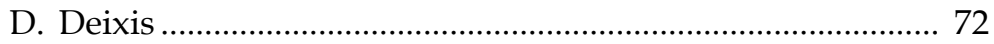

E. Areas of interest ............................................................... 72

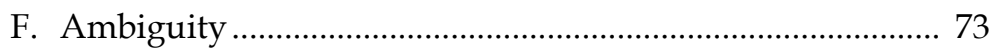

G. Referential uses of language ................................................ 74

CHAPTER 8 SEMIOTICS

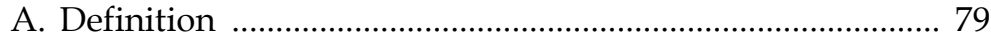

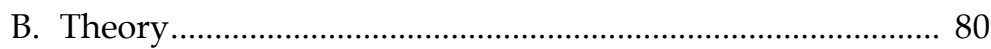

\section{CHAPTER 9 SOCIOLINGUISTICS}

A. Fundamental concepts ......................................................... 89

CHAPTER 10 DISCOURSE ANALYSIS

A. Discourse analysis (DA), or discourse studies ..................... 99

B. Discourse and Frames ......................................................... 100

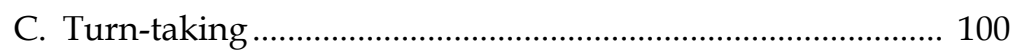

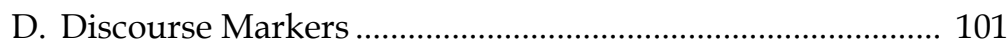

E. Speech Acts ......................................................................... 102

F. Materials that are suitable for discourse analysis 
include:

G. How is discourse analysis different from other

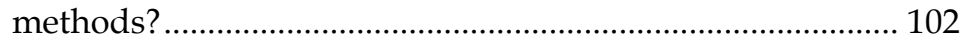

H. How to conduct discourse analysis....................................... 103

I. How Discourse Analysis Differs from Grammar Analysis 105

\section{CHAPTER 11 SYSTEMIC FUNCTIONAL LINGUISTICS}

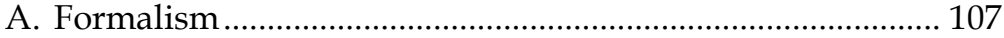

B. Child Language Development................................................ 109

C. Benefits Associated with Working with SFL ......................... 111

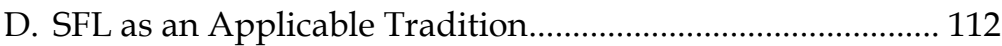

CHAPTER 12 PSYCHOLINGUISTICS

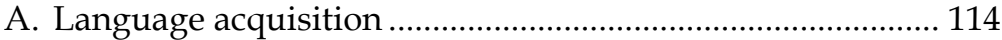

B. Language comprehension ..................................................... 115

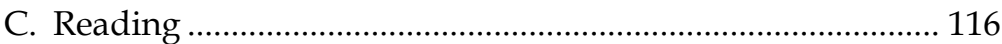

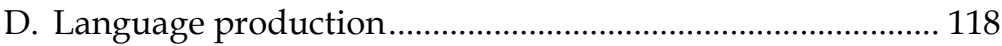

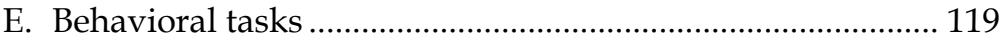

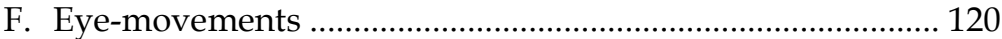

G. Language production errors ……………............................ 120

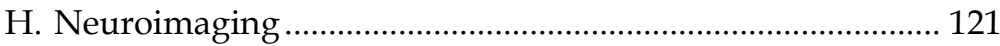

I. Computational modeling ……………………..................... 122

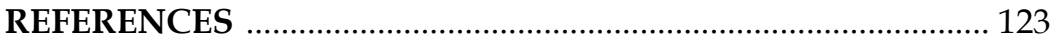




\section{CHAPTER 1 DEFINITION AND BRIEF EXPLANATION ABOUT LINGUISTICS}

Language is all around us. Language allows us to share complicated thoughts, negotiate agreements, and make communal plans. Our learning, our courting, our fighting - all are mediated by language. You can think of language as a technology - humans manipulate their bodies to produce sounds, gestures, and appearances that encode messages using a shared system. How then does the technology of language work? Answering this question is surprisingly hard; our language skills are automatic and therefore hard to reflect upon. Nevertheless, throughout the centuries, scholars have devised ways to study human language, although there is still much more research to be done and many mysteries to explore. The field of scholarship that tries to answer the question "How does language work?" is called linguistics, and the scholars who study it are called linguists.

Linguistics is the scientific study of language. It involves the analysis of language form, language meaning, and language in context. Linguists traditionally analyse human language by observing an interplay between sound and meaning. Linguistics also deals with the social, cultural, historical, and political factors that influence language, through which linguistic and languagebased context is often determined. Research on language through the sub-branches of historical and evolutionary linguistics also focuses on how languages change and grow, particularly over an extended period of time.

Related areas of study include the disciplines of semiotics (the study of direct and indirect language through signs and symbols), literary criticism (the historical and ideological analysis of literature, cinema, art, or published material), translation (the conversion and documentation of meaning in written/spoken text from one language or dialect onto another), and speech-language 
pathology (a corrective method to cure phonetic disabilities and disfunctions at the cognitive level).

\section{A. Historical linguistics}

Historical linguistics is the study of language change over time particularly with regards to a specific language or group of languages. Historical linguistics was among the first sub-disciplines to emerge in linguistics, and was the most widely practised form of linguistics in the late 19th century. There was a shift of focus in the early twentieth century to the synchronic approach (the systemic study of the current stage in languages), but historical research remained a field of linguistic inquiry. Subfields include language change and grammaticalisation studies. Western modern historical linguistics dates from the late 18th century. It grew out of the earlier discipline of philology, the study of ancient texts and documents dating back to antiquity.

At first, historical linguistics served as the cornerstone of comparative linguistics primarily as a tool for linguistic reconstruction. Scholars were concerned chiefly with establishing language families and reconstructing prehistoric proto-languages, using the comparative method and internal reconstruction. The focus was initially on the well-known IndoEuropean languages, many of which had long written histories; the scholars also studied the Uralic languages, another European language family for which less early written material exists. Since then, there has been significant comparative linguistic work expanding outside of European languages as well, such as on the Austronesian languages and various families of Native American languages, among many others. Comparative linguistics is now, however, only a part of a more broadly conceived discipline of historical linguistics. For the Indo-European languages, comparative study is now a highly specialized field. Most research is being carried out on the subsequent development of these languages, in particular, the development of the modern standard varieties. Some scholars have undertaken studies attempting to establish super-families, 
linking, for example, Indo-European, Uralic, and other families into Nostratic. These attempts have not been accepted widely. The information necessary to establish relatedness becomes less available as the time depth is increased. The time-depth of linguistic methods is limited due to chance word resemblances and variations between language groups, but a limit of around 10,000 years is often assumed. The dating of the various protolanguages is also difficult; several methods are available for dating, but only approximate results can be obtained.

The study of languages is conducted with the field of language analysis. Contrary to popular beliefs, linguists are not necessarily polyglots - individuals fluent in many languages. Instead, their primary interest is the scientific study of language. Like a biologist studying the structure of cells, a linguist studies the structure of language: how speakers create meaning through combina- tions of sounds, words, and sentences that ultimately result in texts - extended stretches of language (eg a conversation between friends, a speech, an article in a newspaper). Like other scientists, linguists examine their subject matter - language - objectively. They are not interested in evaluating "good" versus "bad" uses of language, in much the same manner that a biologist does not examine cells with the goal of determining which are "pretty" and which are "ugly." This is an important point because much of what is written and said about language is highly evaluative: many teach- ers tell their students not to use a word like ain't because it is "ignorant" or the product of "lazy" speech patterns ; similar sentiments are expressed in popular books and articles on English usage.

Linguists do have their biases, a point that will be covered later in this chapter in the section on the ideological basis of language, but it is important to distinguish the goal of the linguist - describing language - from the goal of the teacher or writer: pre-scribing English usage, telling people how they should or should not speak or write. Because linguistics is multidisciplinary, specialists in many disciplines bring their 
own expertise to the study of language. Psychologists, for instance, are interested in studying language as a property of the human mind; they have contributed many insights into such topics as how people acquire language.

Anthropologists, on the other hand, have been more interested in the relationship between language and culture, and early work by anthropologists provided extremely valuable information about, for instance, the structure of the indigenous languages of the Americas. Prior to the study of these languages in the early twentieth century, most of what was known about human language was based upon the investment of western languages, such as Greek, Latin, and German: languages that are structurally quite different from the indigenous languages of the Americas. This new knowledge forced linguists to reconceptualize the notion of human language, and to greatly expand the number of linguists subjected to linguistic analysis. Other disciplines - sociology, computer science, mathematics, philosophy, to name but a few - have likewise brought their interests to the study of language.

Despite the many influences on the study of language, it is possible to isolate some basic principles that have guided all studies of language, and it is these principles that will serve as the focus of this chapter. The chap- ter opens with a discussion of language as one part of a larger semiotic system. Semiotic systems are systems of communication and include not just human language but, for instance, gesture, music, art, and dress as well. Like any system, language has structure, and the succeeding sections provide an overview of this structure: the modes (speech, writing, signs) in which language is transmitted, and the conventions (both linguistic and social) for how sounds, words, sentences, and texts are structured. Speakers of English know that the phrase day beautiful is not English because as speakers of English they have an unconscious knowledge of a rule of English sentence structure: that adjectives come before nouns (e.g. beautiful day), not after them. In addition, speakers of English know not to ask 
directions from a stranger by saying Tell me where the museum is because, according to conventions of politeness in English usage, such an utterance is impolite and would be better phrased more indirectly as Could you tell me where the museum is? Because linguists are engaged in the scientific study of language, they approach language, as was noted earlier, "dispassionately," preferring to describe it in an unbiased and objective manner.

\section{B. Studying linguistic structure}

Whether it is spoken, written, or signed, every language has structure, which can be described, as Leech (1983: 21-4) notes, by postulating:

1. rules governing the pronunciation of sounds; the ways that words are put together; the manner in which phrases, clauses, and sentences are structured; and, ultimately, the ways that meaning is created;

2. principles stipulating how the structures that rules create should be used (e.g. which forms will be polite in which contexts, which forms will not).

3. Rules are studied under the rubric of grammar, principles within the province of pragmatics. To understand what is meant by rules and prin- ciples, and why they are studied within grammar and pragmatics, consid- er why a threeyear-old child would utter a sentence such as I broked it [ai broukt $\mathrm{I}$ t] to his father, who just entered a room that the child was play- ing in to discover that the child had broken a wheel off a truck that he had been playing with. To account for why the child uttered I broked it rather than, say, Breaked it I, it is necessary to investigate the linguistic rules the child is using to create the structure that he did.

4. Linguistic rules are different from the rules that people learn in school: "Don't end sentences with preposi- tions"; "Don't begin a sentence with but"; "Don't split infinitives." These are prescriptive rules (discussed in greater detail in the next section) and are intended to provide guidance to students as 
they learn to speak and write so-called Standard English. Linguistic rules, in contrast, serve to describe what people know about language: the unconscious knowledge of language they possess that is part of what Noam Chomsky describes as our linguistic competence. Even though the sentence the child uttered does not conform to the rules of Standard English - the past tense form of the verb break is broke, not broked - it provides evidence that the child is aware of the rules of English grammar. He has applied a past tense ending for the verb, spelled -ed in writing, but has not reached a stage of acquisiion where he is able to recognize the difference between regular and irregular verb forms.

The various rules are part of the study of grammar. Grammar is a word with many meanings. To some, it involves mainly syntax: a study of the parts of speech (nouns, verbs, prepositions, etc.) or syntax in general ("I studied grammar in High School"). To others, it covers usage: correct and incorrect uses of language ("My grammar isn't very good"). For many linguists, however, grammar involves the study of linguistic rules that are part of our linguistic competence: the unconscious knowledge of the rules of a language that any fluent speaker pos- sesses.

Writing a grammar of a language therefore involves codifying the rules that are part of any speaker's linguistic competence: making explicit that in English, for instance, the voicing of a past tense marker depends upon whether the sound preceding it is voiced or unvoiced, or that when a pronoun is used as subject of a sentence the subject form of the pronoun will be used rather than the objective form. When studying rules of grammar, one really does not leave the speaker's brain, since the focus of discussion is the abstract properties of lan- guage that any human (barring disability) is naturally endowed with. But understanding language involves more than describing the psychological properties of the brain. How language is structured also depends heavily on context: 
the social context in which language is used as well as the linguistic context - the larger body of sentences - in which a particular lin- guistic structure occurs. The study of this facet of language is conducted within the domain of pragmatics, which is concerned less with how gram- matical constructions are structured and more with why they have the structure that they do.

In linguistics, language signs are constituted of four different levels, not just two: phonology, morphology, syntax and semantics. Semantics deals with the meanings (what is signified), while the other three are all concerned with the exponent. At the lowest level we find that everything is composed from a small set of sounds, or - when we write-of letters. (Chinese is exceptional in that the alphabet consists of around 50,000 'letters', but each sign stands for a syllable-a sequence of sounds, not just a single one.) With some exceptions (for example tone and intonation) every utterance can be seen as a sequence of sounds. For example, /dog/ consists of three letters (and three sounds): /d/, /o/ and /g/. In order not to confuse sounds (and sound sequences) with letters we denote the sounds by enclosing them in square brackets. So, the sounds that make up [dog] are [d], [o] and [g], in that order. What is important to note here is that sounds by themselves in general have no meaning. The decomposition into sounds has no counterpart in the semantics. Just as every signifier can be decomposed into sounds, it can also be decomposed into words. In written language we can spot the words by looking for minimal parts of texts enclosed by blanks (or punctuation marks). In spoken language the definition of word becomes very tricky. The part of linguistics that deals with how words are put together into sentences is called syntax. On the other hand, words are not the smallest meaningful units of language. For example, /dogs/ is the plural of / dog/ and as such it is formed by a regular process, and if we only know the meaning of /dog/ we also know the meaning of /dogs/. Thus, we can decompose /dogs/ into two 
parts: /dog/ and /s/. The minimal parts of speech that bear meaning are called morphemes. Often, it is tacitly assumed that a morpheme is a part of a word; bigger chunks are called idioms. Idioms are /kick the bucket/, / keep taps on someone/, and so on. The reason for this division is that while idioms are intransparent as far as their meaning is concerned (if you die you do not literally kick a bucket), syntactically they often behave as if they are made from words (for example, they inflect: /John kicked the bucket/). So, a word such as 'dogs' has four manifestations: its meaning, its sound structure, its morphological structure and its syntactic structure. The levels of manifestation are also called strata. (Some use the term level of representation.) We use the following notation: the sign is given by enclosing the string in brackets: 'dog'. [dog]p denotes its phonological structure, $[\operatorname{dog}] \mathrm{M}$ its morphological structure, [dog]l its syntactic structure and [dog]s its semantical structure. For the most part we analyse language as written language, unless otherwise indicated. With that in mind, we have [dog]P $=/ \mathrm{dog} /$. The latter is a string composed from three symbols, /d/, /o/ and /g/. So, ' $\mathrm{dog}^{\prime}$ refers to the sign whose exponent is written here $/ \mathrm{dog} /$. A linguist, then, is not an individual who speaks more than one language, more accurately called "polyglot" or "bilingual" or "multilingual." Rather, a linguist is concerned with language as a human phenomenon. Linguists study grammar, the social and psychological aspects of language use, and the relationships among languages, both historical and present-day. The field of linguistics, like any complex field, includes several major divisions.

\section{Formal Linguistics}

Formal linguistics is the study of the structures and processes of language, that is, how language works and is organized. Formal linguists study the structures of different languages, and by identifying and studying the elements common among them, seek to discover the most efficient way 
to describe language in general. There are three main schools of thought in formal linguistics:

1. The "traditional," or "prescriptive," approach to grammar is probably familiar to most of us. It is what we are usually taught in school. "A noun is a person, place, or thing" is a typical definition in a traditional grammar. Such grammars typically prescribe rules of correct or preferred usage.

2. "Structural linguistics," a principally American phenomenon of the mid-20th century, is typified by the work of Leonard Bloomfield, who drew on ideas of the behaviorist school of psychology. Structuralists are primarily concerned with phonology, morphology, and syntax (described below). They focus on the physical features of utterances with little regard for meaning or lexicon (Crystal, 1980). They divide words into form classes distinguished according to grammatical features. For example, a noun is defined in terms of its position in a sentence and its inflections, such as the "-s" for plural.

3. The "generative/transformational" approach to the study of grammar was introduced by Noam Chomsky in 1957 in his seminal work, "Syntactic Structures." Here he traced a relationship between the "deep structure" of sentences (what is in the mind) and their "surface structure" (what is spoken or written). For example, the surface structure of the sentence, "The postman was bitten by the dog," was derived from the deep structure, "The dog bit the postman," through the application of a passive transformation. From transformational/generative grammar arose the theory of Universal Grammar. This widely accepted theory starts from the perception that all languages share certain linguistic features (universals). The goal of this theory is to explain the uniformity of language acquisition among humans despite ostensible differences in their native languages. Since Chomsky's original proposals in 1957, numerous elaborations and alternative theories have been proposed. 


\section{Formal linguistics includes five principal areas of study:}

"Phonetics" is the study of the sounds of language and their physical properties. Phonetics describes how speech sounds are produced by the vocal apparatus (the lungs, vocal cords, tongue, teeth, etc.) and provides a framework for their classification.

"Phonology" involves analyzing how sounds function in a given language or dialect. For example, /p/ has two possible sounds in English depending on its position in a word. If you place a sheet of paper near your mouth and pronounce the words "pin" and "spin," the paper will vibrate after the /p/ in the first word but not after the same sound in the second word. This puff of air occurs when /p/ is in the initial position of a word in English. Phonologists examine such phonetic shifts to construct theories about linguistic sounds in one language that can be used in comparing linguistic systems. The analysis of sounds in different languages can be very useful for foreign language teachers.

"Morphology" is the study of the structure of words. Morphologists study minimal units of meaning, called "morphemes," and investigate the possible combinations of these units in a language to form words. For example, the word "imperfections" is composed of four morphemes: "im" + "perfect" + "ion" + "s." The root, "perfect," is transformed from an adjective into a noun by the addition of "ion," made negative with "im," and pluralized by "s."

"Syntax" is the study of the structure of sentences. Syntacticians describe how words combine into phrases and clauses and how these combine to form sentences. For example, "I found a coin yesterday" is embedded as a relative clause in the sentence, "The coin that I found yesterday is quite valuable." Syntacticians describe the rules for converting the first sentence into the second.

"Semantics" is the study of meaning in language. The goal of semantic study is to explain how sequences of language are matched with their proper meanings and placed in certain 
environments by speakers of the language. The importance of meaning is revealed in the following well known example from Chomsky (1957): "Colorless green ideas sleep furiously." Though grammatical, this sentence is largely meaningless in ordinary usage.

\section{E. Sociolinguistics}

Sociolinguistics is the study of language as a social and cultural phenomenon. The major divisions within the field of sociolinguistics are described below.

"Language Variation" describes the relationship between the use of linguistic forms and factors such as geography, social class, ethnic group, age, sex, occupation, function, or style. The combination of these various factors results in an individual's "idiolect," that is, their particular and idiosyncratic manner of speech. When a variety of language is shared by a group of speakers, it is known as a "dialect," A dialect, whether standard or nonstandard, includes the full range of elements used to produce speech: pronunciation, grammar, and interactive features. In this respect, dialect should be distinguished from accent, which usually refers only to pronunciation.

All speakers of a language speak a dialect of that language. For example, the speech of an Alabaman is quite different from that of a New Englander, even though the language spoken by both is English. Further differentiation is possible by investigating factors such as social class, age, sex, and occupation.

Language and Social Interaction. This is the province of language and its function in the real world. Three subfields of sociolinguistics investigate this relationship.

1. Pragmatics looks at how context affects meaning. As a function of context, the intended meaning of an utterance is often different from its literal meaning. For example, "I'm expecting a phone call" can have a variety of meanings. It could be a request to leave the phone line free or a reason for not being able to leave the house; or it could suggest to a 
listener who already has background information that a specific person is about to call to convey good or bad news.

2. Discourse analysis examines the way in which sentences relate in larger linguistic units, such as conversational exchanges or written texts. Matters of cohesion (the relationship between linguistic forms and propositions) and coherence (the relationship between speech acts) are also investigated. The links between utterances in sequence are important topics of analysis.

3. Ethnography of communication uses the tools of anthropology to study verbal interaction in its social setting. One example of ethnographic research is the study of doctor-patient communication. Such study involves microanalysis of doctor-patient interaction, noting not only what is said but also pauses between turns, interruptions, questioning and response patterns, changes in pitch, and nonverbal aspects of interaction, such as eye contact.

Language Attitudes. The attitudes people hold toward different language varieties and the people who speak them are important to sociolinguists. Whereas studies in language and social interaction investigate actual language interaction, language attitude studies explore how people react to language interactions and how they evaluate others based on the language behavior they observe.

Language Planning is the process of implementing major decisions regarding which languages should be used on a societal scale. Language attitude studies are an essential component of language planning. In the United States, issues such as establishing bilingual education programs or whether to declare English the official language are major language planning decisions. It is in multilingual nations, however, that language planning is most significant. Governments must decide which of a country's many languages to develop or maintain and which to use for such functions as education, government, television, and the press. "Corpus" planning 
involves the development or simplification of writing systems, dictionaries, and grammars for indigenous languages, in addition to the coining of words to represent new concepts. In such contexts, language planning is an important factor in economic, political, and social development.

\section{F. Psycholinguistics}

Psycholinguistics is the study of the relationship between linguistic and psychological behavior. Psycholinguists study first and second language acquisition and how humans store and retrieve linguistic information, referred to as "verbal processing."

Language Acquisition. The study of how humans acquire language begins with the study of child language acquisition. Principally, two hypotheses have been put forth. The first, deriving from the structuralist school of linguistics, holds that children learn language through imitation and positivenegative reinforcement. This is known as the behaviorist approach. The second, or innateness hypothesis, proposes that the ability to acquire language is a biologically innate capacity. Furthermore, innate language learning ability is linked to physiological maturation and may atrophy around the time of puberty. The innateness hypothesis derives from the generative/transformational school of linguistics.

Such descriptions of language acquisition are further tested in exploring how adults acquire language. It appears that most adults learn language through memorization and positive-negative reinforcement: a manifestation of the behaviorist model. Whether this is a result of the postpubescent decay of the innate ability described above or a result of other psychological and cultural factors is a question of great interest to the psycholinguist.

Verbal Processing involves speaking, understanding, reading, and writing, and therefore includes both the production of verbal output and reception of the output of others. For example, although the sentences of a language may 